\title{
Self-Reflection on Personal Values to support Value-Sensitive Design
}

\author{
Alina Pommeranz, Christian Detweiler, Pascal Wiggers, Catholijn M. Jonker \\ Delft University of Technology \\ Mekelweg 4, 2628CD Delft \\ The Netherlands \\ www.mmi.tudelft.nl \\ \{a.pommeranz,c., c.a.detweiler@tudelft.nl,p.wiggers, c.m.jonker\}@tudelft.nl
}

\begin{abstract}
The impact of ubiquitous technology and social media on our lives is rapidly increasing. We explicitly need to consider personal values affected or violated by these systems. Value-sensitive design can guide a designer in building systems that account for human values. However, the framework lacks clear steps to guide elicitation of stakeholders' values. We argue that developing tools for value elicitation that designers can use or give to stakeholders is a feasible solution to this challenge. Crucial in eliciting values is that a stakeholder has to have an understanding about her own values and how they relate in importance. This requires self-reflection. Self-reflection, in turn, requires thinking or analysing one's behaviour in meaningful moments over a long period of time. In this paper, we investigate how current methods from various disciplines can be combined and applied in a tool supporting reflection on personal values. We present an exploratory study investigating photo elicitation and a value questionnaire as methods for expressing and eliciting values with a tool. Based on the results we present an envisioned mobile personal informatics application that triggers people to reflect about their values in real-life contexts.
\end{abstract}

\section{Value Sensitive Design, Value Elicitation, Personal Informatics, Experience Sampling, Affect}

\section{INTRODUCTION}

As reflected by the conference theme "health, wealth \& happiness", designing for personal values has become increasingly important for technology development. This is due to ubiquitous technology invading our work and private lives on a daily basis. In a multitude of technological systems, e.g. medical applications or social networks, human values (health, privacy, autonomy etc.) play a role and are sometimes violated. System designers are partly responsible for creating socio-technical systems accounting for human values. The valuesensitive design (VSD) framework proposed by Friedman, Kahn and Borning (2006) tries to guide designers in this process. By analyzing which values are relevant for the stakeholders (all parties that interact with the system (users) or are indirectly affected by it) of a system, the design can be driven into the right direction from the start. The framework proposes conceptual, empirical and technical investigations to arrive at a set of relevant values. Whereas VSD supports ethical and philosophical deliberations on the design of new technology, applying it to real life design cases is still difficult. Criticism has come, e.g., from LeDantec and colleagues (2009), pointing out that designers' reflection on a self-proposed set of values will lead to designs of systems aligned with these values rather than systems aligned with values that are relevant for the stakeholders in the context of the design. The authors argue that it is important to integrate the empirical discovery of local values, i.e. those relevant to a given design context and expressed by the stakeholders in the framework. This brings up the question of how to elicit values from stakeholders. As acknowledged by (LeDantec, Poole \& Wyche, 2009), there is an "inherent difficulty in talking about values". Meanings, nuances and interactions of values are complicated to express in a simple ranking of abstract values and difficult to analyze by system designers not trained in (or aware of) value elicitation techniques. Many people do not explicitly reflect on their values and are not aware of their importance. Different stakeholders have different interpretations of abstract values and even a single person's opinion about the importance of a value can change based on her current context. Whereas Friedman and colleagues advocate the use of standard data gathering methods (interviews, surveys etc.) in the empirical investigations, we believe that there is a lack of methods that support the reflection on and elicitation of values in the reallife context. Without a real life context (i.e. 
situations in which a value serves as a guiding principle for a decision or in which the violation of a value is apparent) elicited value profiles might be based on spontaneous thoughts of a person and by that be biased. Also, designer and user/stakeholder might not have a shared understanding of the abstract value concept (such as autonomy) if the context in which the value is relevant is left out. We argue that a good method to elicit values needs to support a person in reflecting on her values over a period of time (e.g. one to several weeks) and in various contexts in order to get a deep understanding of her values.

To support a shared understanding of relevant values between designer (using VSD) and stakeholder we aim at creating a tool for becoming aware and expressing one's values. First, we discuss the concept of values. We then discuss traditional methods used to elicit values. Next, we present an explorative study of the feasibility of some of these methods for value related reflection. We then propose ideas for combining several techniques in a personal informatics tool for people to self-reflect on their values.

\section{PERSONAL VALUES}

Most people have an idea of what they find important in life and some conception of what they consider good, bad, right, and wrong. Such concepts have in common that they all deal with what ought to be as opposed to what is (Pauls, 1990). The former is the subject matter of values. Values play an important role in people's everyday lives. Examples of values include e.g. privacy, trust, autonomy, accountability or environmental sustainability (Friedman, Kahn \& Borning, 2006). As these examples illustrate, values are abstract constructs. However, they are made concrete and instantiated in specific situations (Maio, 2010). For example, valuing privacy translates to not wanting to share one's personal information in a specific context. Similarly, other values function as guiding principles in specific contexts. We refer to this concept of values-in-context as situated values.

Along these lines, we argue that the goodness or badness (or rightness or wrongness) with which a (specific) action, a situation, or other object of evaluation is evaluated stems from a mismatch between what is and what ought to be. As Miceli and Castelfranchi (1989, p. 181) point out regarding the normative character of values, "if something is good, it should be pursued". This is a ground for conflict when people hold different values or different priorities among their values. In the context of design, such discrepancies between designer and stakeholder values are grounds for problems (Kraemer et al., 2010).

\section{METHODS FOR VALUE ELICITATION}

That values are not easy to elicit is illustrated by the amount of research done on understanding values, their interplay with other aspects of human nature and life and the number of inventories produced. Social psychology research resulted in several value inventories and measurement instruments. The Rokeach Value Survey (RVS; ranking 36 values by importance)(Rokeach, 1973), Schwartz Value Survey (SVS) and the Portrait Value Questionnaire (PVQ)(Schwartz \& Bilsky, 1990) are referred to most often; for others see (Cheng \& Fleischmann, 2010). We use Schwartz' and Bilsky's theory of values which sees values as goals that serve as guiding principles in people's lives. With empirical studies he found a list of 10 basic values (achievement, benevolence, conformity, hedonism, power, security, selfdirection, stimulation, tradition, universalism) ${ }^{1}$ that are present regardless of social and cultural background, but differ in importance per person. The PVQ offers personal descriptions, such as " $\mathrm{He}$ likes surprises. It is important to him to have an exciting life", and asks people to rate how similar a described person is to themselves.

Social science researchers have used additional methods to investigate people's values in given contexts. They aim to get a deeper understanding of people's values and their meanings to different aspects in their lives, e.g. through ethnographic studies. In this context some use photo elicitation interviews (Harper, 2002) to get a deep understanding of important aspects of people's lives from their point of view. When participants take their own pictures and discuss them, aspects can arise that the researcher might not have anticipated beforehand.

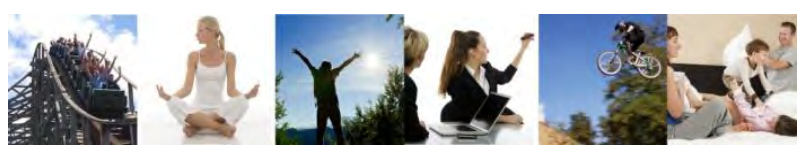

Figure 1: Photos representing excitement, relaxation, freedom, achievement, health, happiness

Photo elicitation evokes feelings and memories, which can give clues to the importance of certain situated values. It has been employed in $\mathrm{HCl}$ to discover user values in the design phase of new technology (LeDantec, Poole \& Wyche, 2009)

\footnotetext{
${ }^{1}$ Achievement (goals, challenge), benevolence (welfare, helping others), conformity (obedience, rules), hedonism (enjoyment, fun), power (social status, dominance), security (health, safety), self-direction (independence, freedom), stimulation (excitement, thrill), tradition (no changes), universalism (justice, equality, peace)
} 


\section{EXPLORING PHOTO ELICITATION AND PVQ FOR REFLECTION ON VALUES}

In an explorative study we compared values elicited from a questionnaire, the $P V Q$, and the photo elicitation method considering how they support people to reflect on values and express them. Questionnaires are used to acquire people's importance rankings of several given values. We chose the PVQ because it differs from other questionnaires in that it does not require the respondents to rate a value directly but uses statements describing a person. Therefore, the result of the questionnaire is independent from a person's interpretation of a value.

\subsection{Set-up}

We asked participants to take at least 10 pictures (work and non-work related) reflecting what they consider important in their everyday lives in the course of one week. We provided an online tool for people to upload and value-tag their pictures. We did not instruct the people to use certain values tags and we did not give a definition of values because we wanted to explore participant's own interpretations of what values are. After one week we asked participants make a selection of pictures for the upcoming interview. A day before the interview we asked participants to fill-in the PVQ. In the interview the participant was asked to go through the pictures one by one and explain why she took a particular picture. The researcher interrupted the participant as little as possible. The interview was filmed. During the interview we also measured physiological data, i.e. heart rate and GSR. Such emotional reactions could be used as an indication of how important a described event was for a participant, and by that may give indication of a values importance. An analysis of this data is outside the scope of this work-inprogress paper.

\subsection{Participants}

Five people ( 3 female, 2 male) participated in the study. We ensured that we interview people with different work and family backgrounds. We had two people (aged 29 and 24) in relationships working 40 hours per week, one as an IT consultant in a big international company $(P 1)$ and one as a communications manager in a research company $(P 2)$. One participant (aged 53) worked between 40-50 hours per week as a senior manager in a major consulting company $(P 3)$. This participant was married and had two adult children. Two participants (aged 36 and 37) worked half-time (24 hours per week) at a university $(P 4 \& P 5)$. Both were married and had small children.

\subsection{Results}

\subsubsection{Comparison of elicited Values}

To understand how people express and reflect on their values and in how far taking pictures in an everyday context supports this self-reflection, we investigated the words people used to tag their pictures and the self reports in the interview. Two researchers viewed the videos and extracted statements that reflected what a person considered important. This included statements explicitly naming a value (e.g. "It is nice to have that freedom", P1) or implicitly referring to a value ("My parents are important to me. I can rely on them" e.g. reflecting trust or safety, $P 4)$.

To explore if different methods of eliciting values we compared the results from the methods we used in this study. Table 1 shows a comparison of values elicited by the PVQ instrument, by the researchers based on the interviews (reflecting the main themes the participants discussed) and people's own tags. The PVQ results in a ranking over all 10 values named in Schwartz' theory. In table 1 we only consider the higher ranked values (from most important to less important) for each participant based on a mean calculation for each value construct $(M \geq 3)$. This reflects only values that were rated with "somewhat like me", "like me" and "very much like me". In the comparison of the elicited values from the three sources we had to match the labels people used in their tags and the interviews to the abstract values that the PVQ elicits. As an example, we related labels like fun, enjoyment, happiness to hedonism, and creativity, freedom, work-life balance to self-direction. Next, we compared per participant whether the values elicited with the PVQ were reflected in the tags and the interview. We found that a majority of values were indeed reflected in all three methods. A notable exception was the value "universalism" which was elicited by the PVQ in three cases but was not reflected in people's accounts of important aspects in their life. Only P3 hinted at universalism, when talking about his tolerance towards his children. Besides the overlap, there are differences in all five cases. Especially in case of P3 and P5 the interview and the tagging revealed several values that seemed of great importance for the participant but were not highly ranked by the PVQ. P3 mentioned his orientation towards results, recognition, being proud as well as organized and efficient. These aspects clearly relate to achievement, which was not an important value resulting from the PVQ. For P5 several values mentioned in our study, i.e. organization, efficiency, health, challenge, were not revealed by the PVQ. In this case we can tentatively conclude that the PVQ did not work well for the participant, as shown by the small number of values (self-direction, hedonism) resulting in higher than average ratings. 
Table 1: Comparison of Values elicited from different sources

\begin{tabular}{|c|c|c|c|}
\hline \multirow[t]{2}{*}{ Participant } & \multicolumn{3}{|c|}{ Elicited Values } \\
\hline & PVQ Results & $\begin{array}{l}\text { Interview Results (values elicited by } \\
\text { researchers) }\end{array}$ & Tags used by participant \\
\hline$P 1$ & $\begin{array}{l}\text { 1. hedonism, } \\
\text { 2. achievement, } \\
\text { 3. universalism, } \\
\text { 4. self-direction }\end{array}$ & $\begin{array}{l}\text { - Fun, enjoyment, excitement } \\
\text { - Nice colleagues \& interesting work (job } \\
\text { satisfaction) } \\
\text { - Getting work done, perfection } \\
\text { - Freedom, flexibility (working from home) } \\
\text { - Security }\end{array}$ & $\begin{array}{l}\text { Responsibility }(2 x), \\
\text { fun( } 2 x), \text { accomplishment, } \\
\text { frustration about commute }(2 x), \\
\text { pride, happy, relaxation, calm, } \\
\text { productive, love, happiness }\end{array}$ \\
\hline$P 2$ & $\begin{array}{l}\text { 1. self-direction, } \\
\text { 2. stimulation, } \\
\text { 3. achievement, } \\
\text { 4. hedonism/ } \\
\text { universalism/ } \\
\text { benevolence }\end{array}$ & $\begin{array}{l}\text { - Community/ being social (friends, family, } \\
\text { colleagues), } \\
\text { - Learning/Exploring new things (cultures, } \\
\text { hobbies, people), } \\
\text { - Independence/Freedom (at work and at } \\
\text { home), relaxed work atmosphere }\end{array}$ & $\begin{array}{l}\text { friends(5), parties( } 2 x), \text { healthy, } \\
\text { nice working atmosphere, good } \\
\text { company (e.g. pets), freedom, } \\
\text { self-sufficiency, space, } \\
\text { relaxation( } 2 x) \text {, self-organization, } \\
\text { being creative, learning/study } \\
(5 x), \text { challenge, meeting } \\
\text { people }(2 x), \text { experience }\end{array}$ \\
\hline$P 3$ & $\begin{array}{l}\text { 1. hedonism, } \\
\text { 2. self-direction/ } \\
\text { benevolence, } \\
\text { 3. universalism }\end{array}$ & $\begin{array}{l}\text { - Fun, enjoyment, balance between hard work } \\
\text { and fun, team spirit, } \\
\text { - Results, recognition, achievement (at work), } \\
\text { being proud (work and family), } \\
\text { - Organisation, efficiency } \\
\text { - Relaxation, Health } \\
\text { - support of others (family and work) }\end{array}$ & $\begin{array}{l}\text { fun }(3 x), \text { results }(2 x), \text { good } \\
\text { discussions, organize, relaxing, } \\
\text { proud }(2 x), \text { recognition, team } \\
\text { spirit, quality time, being } \\
\text { available, healthy, set goals, } \\
\text { rest, moment for yourself }\end{array}$ \\
\hline$P 4$ & $\begin{array}{l}\text { 1. self-direction, } \\
\text { 2. hedonism/ } \\
\text { security }\end{array}$ & $\begin{array}{l}\text { - Family } \rightarrow \text { safety, most important } \\
\text { - Being social (sporting in big group) } \\
\text { - Good work atmosphere, social moments, } \\
\text { nice colleagues } \\
\text { - Work-life balance, Freedom } \\
\text { - Proud }\end{array}$ & $\begin{array}{l}\text { Safety }(2 x), \text { love }(2 x), \text { security, } \\
\text { creativity, job satisfaction }\end{array}$ \\
\hline P5 & $\begin{array}{l}\text { 1. self-direction } \\
\text { 2. hedonism }\end{array}$ & $\begin{array}{l}\text { - Team work, good atmosphere, helping each } \\
\text { other, fun } \\
\text { - Thinking positive (negativity costs energy) } \\
\text { - Organisation, Practical, Efficiency } \\
\text { - Creativity } \rightarrow \text { Perfection } \\
\text { - Health, Challenge (sport) }\end{array}$ & $\begin{array}{l}\text { Good teamwork, nice feeling, } \\
\text { good work atmosphere, having } \\
\text { facilities close by, practical, } \\
\text { close relationship to parents, } \\
\text { happy, hobby }\end{array}$ \\
\hline
\end{tabular}

\subsubsection{Comments on the Methods}

Except participant $\mathrm{P} 1$ everyone mentioned that filling in the PVQ was difficult. P2 said that she often felt that the first sentence of the described person fitted her well, but when she read on, the person was not similar to her. Generally, people liked taking pictures in their daily lives. P1 thought it was difficult, however, to take pictures of reoccurring everyday situations that are connected to values. Despite this P1 did not seem to have difficulties talking about the pictures. Although some of his pictures showed rather everyday things, they triggered long elaborations of specific situations important to him. This was the opposite for P2, who took many pictures showing several aspects of her life, but kept the descriptions during the interview rather short. P3 enjoyed taking the pictures and even more talking about important aspects in his life. He mentioned trying to tag the photos with one value-related word was often difficult. The same difficulty was reported by P4. Both succeeded after some time of reflection to put value related tags. In case of P3 the tags reflected well what he focussed on during the interview, whereas in case of P4 some aspects discussed were missing in the tags. P5 circumvented the tagging difficulty by writing full sentences for each picture. She liked that the tasks (taking pictures, answering questionnaire, interview) were easy to follow and, therefore, enjoyed taking part.

\subsubsection{Conclusions}

From the comparisons of values elicited from the different sources and the comments of the participants we can conclude that there are individual differences between people in how they can express their values and which methods support this process. Based on this we believe that triangulation is an important aspect when designing a tool that helps people to reflect on and express their values. By that we mean that we have to collect different types of data and allow people to analyse the collected data from different perspectives. This could, e.g., mean that a visually oriented person can easily cluster images taken and ask the system to retrieve all tags and emotions connected to the clusters to find patterns. A person that can express herself better in words 
could start with clustering tags and then review the images that have these tags to find out in which situations a value played a role in her life. We also saw that some participants need guidance in getting from their self-reflections to explicitly stating values. Emotional reactions may give an indication of how important certain situations and the affected values are. Querying participants about their mood or emotion connected to a situation will help selfreflection. We are still analyzing the heart rate and skin conductance data to see if physiological measurements can be utilized in this process as an objective evaluation.

\section{TOWARDS A MOBILE APPLICATION TO SUPPORT SELF-REFLECTION ON VALUES}

Following from our observations that people prefer different ways of expressing values and reflect differently on their values, there is a need for a tool supporting these differences and guiding the person in explicit value deliberations. Similar differences in expressions (e.g. logical, linguistic, interpersonal or bodily) were also found by Voida and Mynatt (2005) in a study of conveying family values to designers. Based on the results of our study we present ideas for a mobile application for support of self-reflection on values. The application will help stakeholders to first reflect on situated values by using it in everyday life contexts over a period of at least several days and then be able to express the importance of and relations between values to the designers.

A recent area serving as inspiration for creating our mobile tool is Personal Informatics (PI). PI systems support people in collecting information about their lives to self-reflect and gain self-knowledge ( $\mathrm{Li}$, Dey, Forlizzi, 2010). They identify two core aspects of every PI system, namely collection (collecting information about oneself) and reflection (reflecting on personal information). Although PI systems are usually not used as value elicitation tools, several systems implicitly focus on values, e.g. by trying to improve people's health or happiness (see personalinformatics.org/tools).

We envision a PI system collecting contextual information in meaningful moments. Users can reflect on and analyze the collected data at a later stage. More importantly, for becoming aware of situated values, people are asked to reflect immediately in the situation where a value might be affected. This means that meaningful "reflection moments" have to be identified by the application or logged by the user. Using smartphones opens up several possibilities for identifying important moments and collecting contextual information. The application can either make use of sensors embedded in the system (e.g. using the Sense technology www.sense-os.nl) or external sensors, e.g. biosensors. The utility of using heart rate, skin conductance and temperature as indicators of meaningful or memorable moments has been investigated by Kelly and Jones (2009) in the area of retrieving interesting life-logging data. They found, among others, a correlation between the importance of retrieved events from the SenseCam they used and the maximum GSR values. We will explore the possibility of using real-time skin conductance or temperature data in one of the upcoming prototypes. Taking into account that some important (high arousal) situations can also be sensitive or even restrict the person from giving feedback, immediate feedback will be voluntary. The user can still decide to log the reflection moment after it occurred.

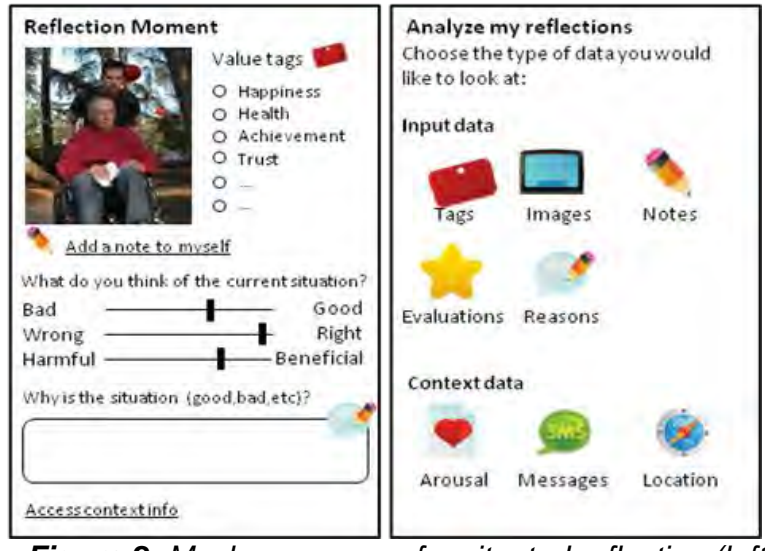

Figure 2: Mock-up screens for situated reflection (left) and analysis (right)

Important for reflection on situated values is not only identifying the right situations, but also making the user aware of the context. Therefore, the application will ask users to take a photograph and tag it with value-related words (if possible). To further guide people in explicitly reflecting on situated values (and help designer's to understand stakeholders' values) the Experience Sampling Method (Consolvo, 2003) can be employed, which asks the user to fill in quick questionnaires whenever a trigger event occurred.

Since values deal with varieties of goodness, users of the tool will be asked to evaluate the situation they are in, in terms of good or bad, right or wrong, beneficial or harmful (see Figure 2, left screen). The evaluation of the situation will be followed by a request to provide (brief) reasons for the particular evaluation the user selected, the underlying assumption being that the evaluation stems from the difference between what is (the situation) and what ought to be (the value). By asking why a particular situation is, for example, bad, users should provide reasons that indicate that the situation does not match "what ought to be". Providing such reasons should be optional, so as not to burden users. 
By logging physiological, quantitative and qualitative context data we enable a triangulation of data that can lead to a better self-reflection suited to personal preferences (visual, textual, etc.). Besides the in-situ functionality described so far the application will offer functionality to review and analyze the logged data at any point in time (see Figure 2, right screen). Again a focus will be put on triangulation and personal preferences for reviewing the data from different angles. To design the tool in a way that supports the differences of people and does not intrude people's privacy we will follow a user-centered design process, providing several iterations of prototyping and insitu evaluation.

\section{CONCLUSIONS}

In this paper we argued for including elicitation of stakeholders' situated values into value-sensitive design processes. To enhance the communication between designers and stakeholders a shared understanding is necessary, which in turn can only be achieved if both parties have a clear understanding of their own values. Many people lack this understanding. We proposed a mobile tool guiding people in self-reflecting on their values in everyday contexts. Value-sensitive designers can use values elicited with the tool when interviewing stakeholders to define more explicit requirements to support values in the system design.

\section{ACKNOWLEDGEMENTS}

The research is supported by the Dutch Tech. Foundation STW of NWO and the Tech. Program of the Ministry of Economic Affairs and part of the Pocket Negotiator project ( $\mathrm{VICl}-08075)$.

\section{REFERENCES}

Bardi, A. and Schwartz, S. H. (2003). Values and Behavior: Strength and Structure of Relations. Personality and Social Psychology Bulletin, 29, 1207-1220.

Cheng, A.-S. and Fleischmann, K. R. (2010). Developing a meta-inventory of human values. Proceedings of the American Society for Information Science and Technology, 47, 1-10.

Consolvo, S. and Walker, M. (2003). Using the Experience Sampling Method to Evaluate Ubicomp Applications. IEEE Pervasive Computing, 2, 24-31.

Friedman, B., Kahn, P., and Borning, (2006). A. Value Sensitive Design and Information Systems. In P. Zhang and D. Galletta (eds.), HumanComputer Interaction and Management Information
Systems: Foundations (pp. 348--372). .E. Sharpe, New York.

Harper, D. (2002). Talking about pictures: a case for photo elicitation. Visual Studies, 17, 13-26.

Kelly, L. and Jones, G.J.F. (2009). Examining the Utility of Affective Response in Search of Personal Lifelogs. 5th Workshop on Emotion in $\mathrm{HCl}$, British $\mathrm{HCl}$ Conference,

LeDantec, C. A., Poole, E. S. \& Wyche, S. P. (2009). Values as lived experience: evolving value sensitive design in support of value discovery. Proceedings of the 27th international conference on Human factors in computing systems. Boston, MA, USA: ACM.

Li, I., Dey, A. and Forlizzi, J. (2010). A stage-based model of personal informatics systems. Proceedings of the 28th international conference on Human factors in computing systems. Atlanta, Georgia, USA: ACM.

Maio, G. R. (2010). Mental Representations of Social Values. Advances in Experimental Social Psychology, 42, 1-43.

Miceli, M. and Castelfranchi, C. (1989). A Cognitive Approach to Values. Journal for the Theory of Social Behaviour, 19, 169-193.

Pauls, R. (1990). Concepts of Value: A MultiDisciplinary Clarification. Lincoln, N.Z.: Centre for Resource Management.

Rokeach, M. (1973). The nature of human values. New York: Free Press.

Schroeder, M. (2008). Value Theory. In: Zalta, E. N. (ed.) The Stanford Encyclopedia of Philosophy. Fall 2008 ed.

Schwartz, S. H. and Bilsky, W. (1990). Toward a Theory of the Universal Content and Structure of Values: Extensions and Cross-Cultural Replications. Journal of Personality and Social Psychology, 58, 878-891.

Slovic, P., Finucane, M. L., Peters, E. and Macgregor, D. G. (2007). The affect heuristic. European Journal of Operational Research, 177, 1333-1352.

Spates, J. L. (1983). The Sociology of Values. Annual Review of Sociology, 9, 27-49.

Turney, P. D. (2002). Thumbs up or thumbs down?: semantic orientation applied to unsupervised classification of reviews. Proceedings of the 40th Annual Meeting on Association for Computational Linguistics. Philadelphia, Pennsylvania: Association for Computational Linguistics.

Voida, A. and Mynatt, E. D. (2005). Conveying user values between families and designers. $\mathrm{CHI}$ '05 extended abstracts on Human factors in computing systems. Portland, OR, USA: ACM. 